\title{
Product Recommendation Based on Eye Tracking Data Using Fixation Duration
}

\author{
Juni Nurma Sari ${ }^{1,2}$, Lukito Edi Nugroho ${ }^{3}$, Paulus Insap Santosa ${ }^{4}$, Ridi Ferdiana ${ }^{5}$
}

\begin{abstract}
E-commerce can be used to increase companies or sellers' profits. For consumers, e-commerce can help them shop faster. The weakness of e-commerce is that there is too much product information presented in the catalog which in turn makes consumers confused. The solution is by providing product recommendations. As the development of sensor technology, eye tracker can capture user attention when shopping. The user attention was used as data of consumer interest in the product in the form of fixation duration following the Bojko taxonomy. The fixation duration data was processed into product purchase prediction data to know consumers' desire to buy the products by using Chandon method. Both data could be used as variables to make product recommendations based on eye tracking data. The implementation of the product recommendations based on eye tracking data was an eye tracking experiment at selvahouse.com which sells hijab and women modest wear. The result was a list of products that have similarities to other products. The product recommendation method used was item-to-item collaborative filtering. The novelty of this research is the use of eye tracking data, namely the fixation duration and product purchase prediction data as variables for product recommendations. Product recommendation that produced by eye tracking data can be solution of product recommendation's problems, namely sparsity and cold start.
\end{abstract}

Keywords-E-commerce, Consumer Interest in the Product, Product Purchase Prediction, Eye Tracking, Product Recommendations.

\section{INTRODUCTION}

When shopping, there are several factors influencing the desire to buy goods, such as needs, desire to own a new item, or to replace the old stuff. The purpose of shopping affects consumer behavior in shopping and affects the time of shopping. Consumers who have the shopping purpose to buy needs require less time than consumers who have a shopping purpose because of desire. It happens because the desire to have a good product affects the product selection time.

The previous behaviors also apply when consumers shop online. In e-commerce, there are many products in a catalog. When consumers do not have a clear shopping purpose, the catalog will confuse them. Consumers accept much information about the product, so they have overloaded information. As the

Informatic Engineering, Department of Information Technology, Politeknik Caltex Riau, Jln Umban Sari No 1, Rumbai, Pekanbaru, 28261, INDONESIA (phone: 0761-53939; e-mail: 1juni@pcr.ac.id)

2,3,4,5 Department of Electrical and Information Engineering, Faculty of Engineering, Universitas Gadjah Mada, Jln. Grafika No. 2, Kampus UGM, Yogyakarta, 55281, INDONESIA (phone: 0274552305; email:2juni.s3te14@mail.ugm.ac.id,3lukito@ugm.ac.id, 4insap@ugm.ac.id, ${ }^{5}$ ridi@ugm.ac.id) solution of that condition and to shorten the time of shopping, e-commerce can provide product recommendation. Product recommendation is one of the personalization techniques that provides recommendations to consumers with the list of products that are in demand, the list of products that are similar to other products, and so on [1], [2].

There are various product recommendation techniques, such as collaborative filtering, content-based method, and contentbased collaborative filtering. Collaborative filtering is a frequently used method of the product recommendations. Although this method is very simple, it can provide better information. The development of collaborative filtering methods has been widely done, such as item-to-item collaborative filtering [2] and fuzzy based collaborative filtering [1]. Collaborative filtering uses information of data transaction and data rating of product that are provided by consumers after making a purchase.

Product rating data is the rating of product given by consumers. It means consumers are interested in that product. Thus, the product rating data is data of consumer interest in a product. Product rating data are usually given by consumers when they do the transaction [3]. Hence, consumers can give a rating to product when they buy the product. In other words, not all consumers can give rating to product. Another way to get consumer interest is by clicking that product, and that data is collected in data clickstream [4] or web server log [5]. Both ways need consumer interaction with e-commerce.

The technology to detect motion has been developed. This technology is widely used for games. Detection of this motion uses infrared (passive and active sensors), optics (camera and video), radio frequency energy (radar, microwave sensor detection), sound (microphones and acoustic sensor), vibration (seismic sensor) [6]. Tools for detecting motion using infrared are Kinect, Leap Motion, and Eye Tracker.

Eye Tracker is a tool to detect eye movements. The detection of the eye movements can be used for a variety of purposes, such as knowing the concentration of the user, knowing the consumer's attention to a product, and the detection of eye movements for games [7]-[9]. Eye movements are captured by an eye tracker, and then they are processed into fixation duration data. With this data, the consumer attention to products, especially e-commerce products can be determined when consumers shop online. The duration of the fixation data is the length of time consumers used to perceive a product. It is analyzed by using Chandon method to obtain the prediction data of product purchase [10]. Both data can be used as product recommendations.

This study discusses product recommendation model using item-to-item collaborative filtering involving fixation duration and product purchase prediction data. Fixation duration data are 


\section{For each item in product catalog, $I_{1}$ \\ For each consumer $C$ who purchased $I_{1}$ \\ For each $I_{2}$ purchased by consumer $C$ \\ Save consumers who purchased $I_{1}$ and $I_{2}$ \\ For each item $\mathrm{I}_{2}$ \\ Calculate the similarity between $I_{1}$ and $I_{2}$}

Fig. 1 Item-to-item collaboration filtering

the data of the consumers' attention to certain products that they see, meanwhile the product purchase prediction data are the results of data processing from the fixation duration data.

Discussions of the product recommendations using the fixation duration and predictive data of the proposed product are divided into several sections. Section II discusses the weaknesses and strengths of e-commerce. Section III discusses the product recommendation as one of the weaknesses of ecommerce solution. Section IV discusses the method of product recommendation and item-to-item collaboration filtering. Section V discusses the eye tracking technology. Section VI discusses data processing of consumer interest of product and product purchase prediction data. Section VII discusses product recommendations based on eye tracking data. Section VIII presents product recommendations experimented using the eye tracking technology and discussion. The last section, namely section IX, presents the conclusion.

\section{E-COMMERCE}

Internet technology can be used to improve business processes of a business section, such as by building an ecommerce site to help consumers shop online. E-commerce is a way to increase profits and to achieve other goals of a business or company using internet technology [11]. In the ecommerce, there are several categories, namely business to consumer (B2C), business to business (B2B), business process (BP), consumer to consumer $(\mathrm{C} 2 \mathrm{C})$, and business to government (B2G) [12]. Currently, the most developed businesses are $\mathrm{B} 2 \mathrm{C}$ and $\mathrm{C} 2 \mathrm{C}$. In this research, $\mathrm{B} 2 \mathrm{C}$ ecommerce is used as the experimental material.

In e-commerce, information of marketed products can be seen in the goods catalog. However, the number of products displayed on the goods catalog leads users to have difficulties to obtain information that is needed. The weaknesses in ecommerce are the abundance of product information [13] and overloaded information [14], product dissemination [15] and product complexity [16] which cause overloaded information. The solution of overloaded information is to provide personalized e-commerce services in the form of the product recommendations, including products that are highly purchased, products purchased by other consumers who buy the same products. The existence of the product recommendations will quicken consumers to choose the products and even purchase them.

\section{PRODUCT RECOMMENDATION}

Variables required for the product recommendations are customer purchase, rating, items viewed, demographic data, subject interest, and favorite artist [2]. Several methods can be used for the product recommendations, namely traditional collaborative filtering, cluster model, search base method and item-to-item collaborative filtering; the latter is proposed by [2].

Collaborative filtering and cluster models almost have the same method, with the first step is to find a group of consumers who make purchases, then rate the items purchased by some consumers, conduct consumers segmentation, and collect data items purchased by the consumers. The next step is to eliminate items that have been purchased and rated by the consumers. The last step is to make recommendations for other items. Search based model and item-to-item collaborative filtering methods also have the same method. The first step is to collect the data items purchased by consumers, rate the items, and then look for similar items from the data to provide recommended items.

Other methods for product recommendations include Bayesian network, clustering technique and Horting method [1]. Bayesian network method uses the decision tree with information from consumers presented with nodes and edges, using training data. Clustering technique method identifies groups that have similar interest predictions by performing an average calculation of choices, and the results are recommendations. Horting method uses graph method where the node is consumer information, while the edge is weighted information of similarity among consumers. The proposed method of [1] is fuzzy collaborative filtering, a development of collaborative filtering based on item-based recommendation. Reference [1] made fuzzy inference system (FIS) with inputs of average rating from user choice similarity and average rating from acceptance rate with low, medium, and high value. The outputs are from very low, low, medium, high, and very high.

Reference [1] and [2] stated that item-based recommendation has advantages over user-based recommendation [1], [2], [17], which can increase scalability, real-time, can be used for large data, can provide high quality recommendations and the calculation does not depend on the number of consumers and the number of items [2].

\section{ITEM-TO-ITEM COLLABORATIVE FILTERING}

Item-to-item collaborative filtering method needs product rating data and transaction data. Product rating data is the consumer interest data or the consumer assessment data on the product. Transaction data is the data of product purchased by a consumer.

Item-to-item collaborative filtering algorithms begins with detection the item or product $I_{1}$ that is purchased by consumer C. The next step is to detect other product that is purchased by consumer $\mathrm{C}$ and stored at Arraylist. After getting all data, the consumer that purchases $I_{1}$ and other product then calculate the similarity between those products. All process is repeated until the last product. Fig. 1 describes the algorithm of the item-toitem collaborative filtering [2].

Similarity method that is used in item-to-item collaborative filtering is Pearson correlation coefficient. The method is in (1).

$$
\operatorname{sim}(i, j)=\frac{\sum_{u \in U}\left(R_{u, i}-\bar{R}_{i}\right)\left(R_{u, j}-\bar{R}_{j}\right)}{\sqrt{\sum_{u \in U}\left(R_{u, i}-\bar{R}_{i}\right)^{2}} \sqrt{\sum_{u \in U}\left(R_{u, j}-\bar{R}_{j}\right)^{2}}}
$$




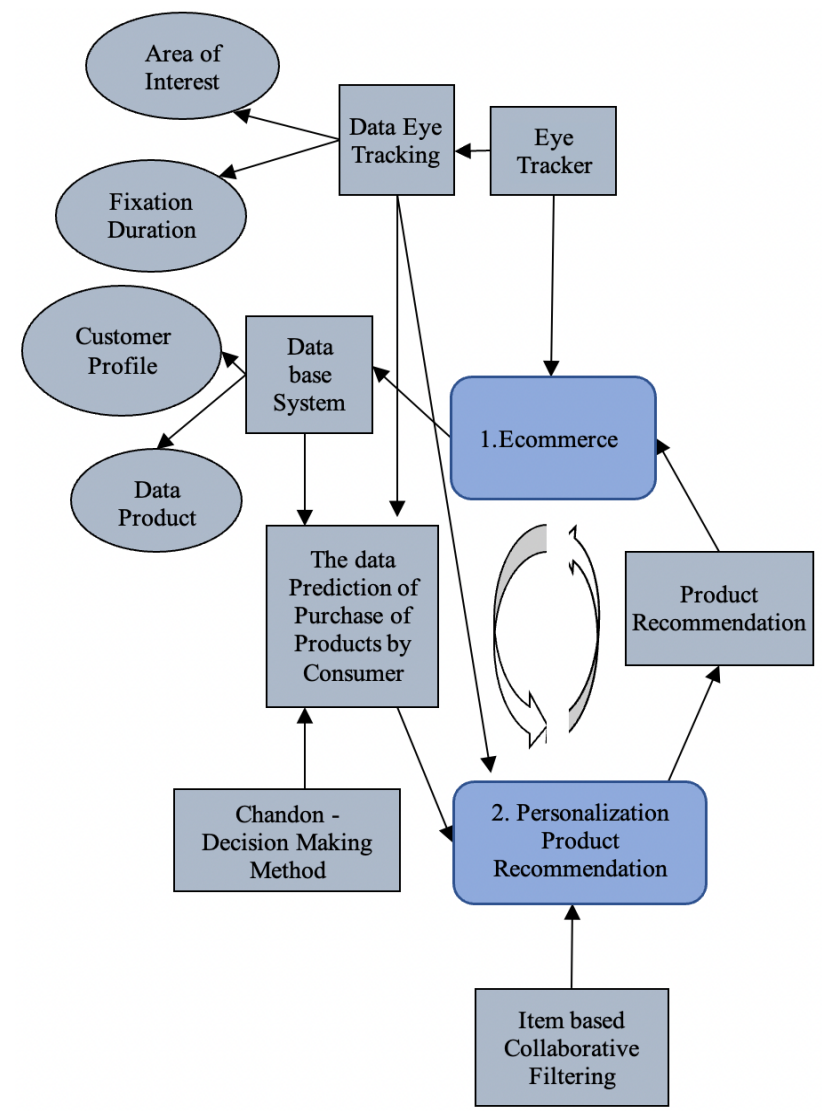

Fig. 2 Model of product recommendation based on eye tracking data.

where $\operatorname{sim}(i, j)$ is similarity between item $i$ and item $j, R_{u, i} \mathrm{I}$ is rating user $u$ on item $i, R_{u, j}$ is rating user $\mathrm{u}$ on item $j, \bar{R}_{i}$ is the average rating on item $i$, and $\bar{R}_{j}$ is the average rating on item $j$.

This research uses the item-to-item collaborative filtering to develop product recommendations based on the consumer interest in the products. The consumer interest was captured based on the consumer attention data by using eye tracking method.

\section{Eye Tracking TeChNOLOGY}

The development of sensor technology to detect the human body parts has also been growing rapidly. The human body parts detected are, for example, the hands, face, eyes, and other human body parts movements. The development of sensor technology is followed by the development of several applications, such as learning application on composing shape by catching hand gesture for children, music game through hand gesture, to know the emotion of someone through face tracking, to know consumer interest to the product through the consumer attention using the eyes, and to know the consumer's concentration through capturing eye movements.

In marketing, consumer attention to the product is very important as it helps to know the consumer interest in the product. The earlier to recognize consumer interest in the products, the easier to help the consumer chooses the preferred and desired products. It is because by using the user attention, products favored by consumers can be detected without going through the transaction process or without buying the product, so that it will shorten the shopping time.

User attention to the products can be used to recognize the user interest in the product. The longer the eyes of consumers view the product, the more interested the consumer is in the product. User attention is captured by the eye tracker, the tool for detecting eye movements. User attention data are obtained from the eye view position to the product area which is fixation. The product area of the eye tracking technology is called area of interest (AOI). User attention to the AOI is calculated in duration so that the length of the eye view of the specified product is the duration of the fixation data that can be processed into predictive data to recognize whether consumers are willing to buy the product or not.

\section{Eye Tracking Data Processing and PRoduct PURCHASE PREDICTION}

The data processing of the eye tracking uses several methods such as the Aga Bojko method which is used to know the consumer interest in the product [18], and the Chandon method which is used to know the prediction whether the consumer wants to buy the product or not [10]. Both methods are discussed as follows.

\section{A. Consumer Interest in E-Commerce Products}

The Aga Bojko method can be used to measure consumer interest in an object and to know the performance of an object by using the eye tracking technology [18]. The method was used to compare the user interest in the old company's web design with the new one. The result showed that users were more interested in the new design.

The measurement of the product interest in e-commerce can use the measurement of the area interest measures, using three metrics such as calculating the amount of fixation on AOI, calculating the total dwell time, in this case the fixation duration and the time percentage when viewing AOI such as comparison between total duration fixation on AOI and total fixation duration on all AOI. In comparing the three metrics, it was found that the duration fixation metric indicated consumer interest and retrieved simple fixation duration data [19]. In the previous research, there is a relation between consumers' interest in e-commerce product and selected product [19].

\section{B. Prediction of Consumers Purchase Product Desire}

Several studies discuss the consumer prediction of buying a product. Components that affect the consumers' desire to purchase are the evaluation or experience of the product [10]; the need for the product [10]; interest in the product [10], [20], [21]; product price [20]; product location [21]; and product search patterns [21].

Reference [10] proposed a consumer prediction model to buy simple goods by considering consumer memory of products in the form of evaluation, experience, and the need for products stated with Betha and consumer attention to products stated with Alpha. The prediction data in this study used the Chandon model. The previous research used Chandon model as measurement of the prediction of product selection [22]. 


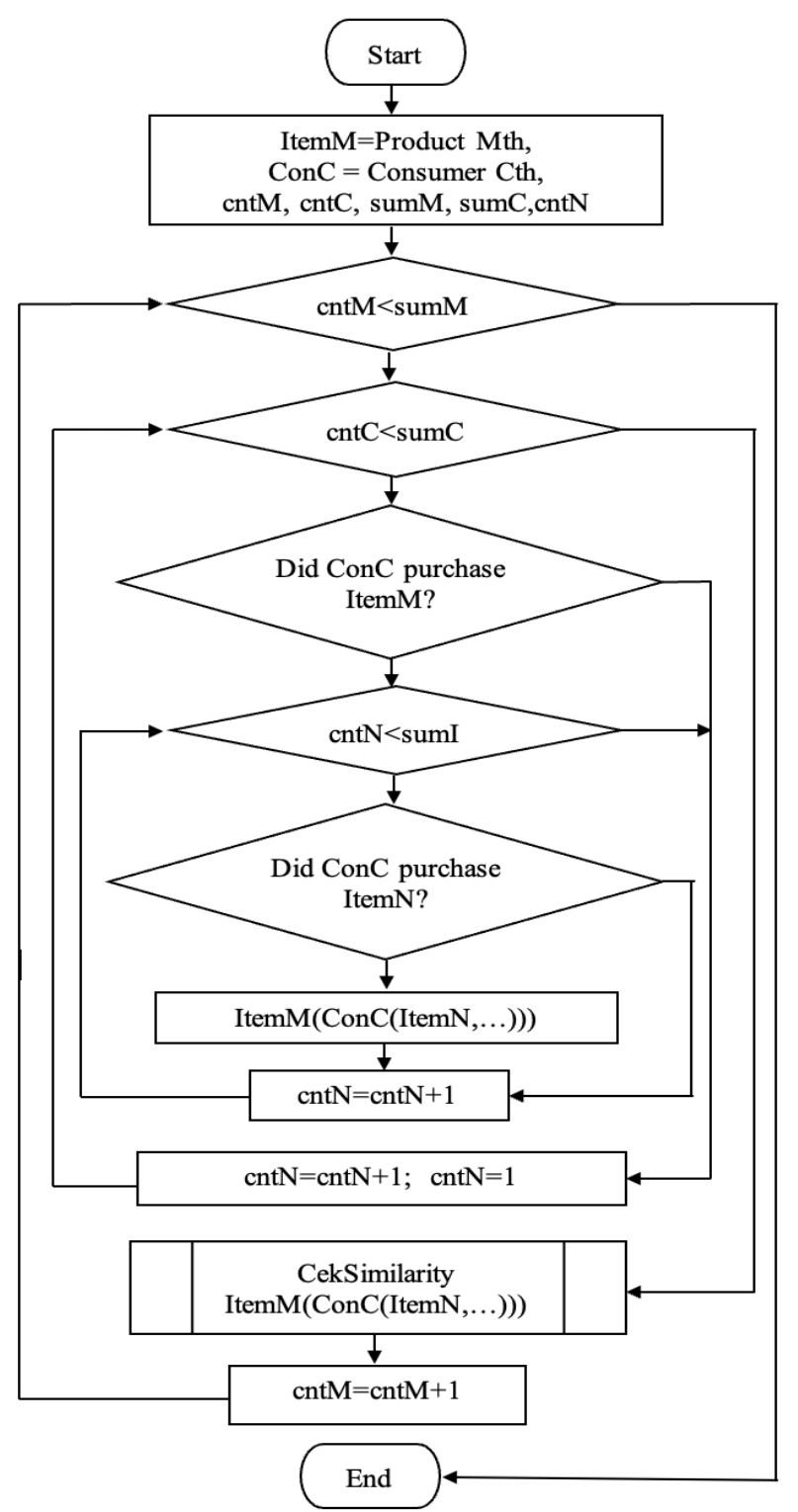

Fig. 3 Flowchart of item-to-item collaborative filtering.

\section{Product Recommendations BASEd on DATA Eye TRACKING}

The product recommendation is a solution to overloaded information experienced by consumers when shopping due to a great number of products offered. The existence of the product recommendations will reduce the time of consumers in shopping, especially when choosing the product. Variables required on the product recommendations are transaction data and consumer rating data on the product. Both data are obtained after the consumer makes a transaction.

The product recommendations can be obtained when consumers shop, by using consumer interest data on product and purchase prediction data, where the prediction data can represent transaction data, meanwhile interest data represent data rating. The eye tracking technology can be used to retrieve data of the consumer interest in the product, and then the data are analyzed to get the prediction data of the product purchased by consumers. The advantage of the product recommendations based on the eye tracking data is that the consumers will get a list of the products according to interest and desire so that the product recommendations are given earlier before the transaction.

On the model of the eye tracking based-product recommendations which is shown in Fig. 2, the consumer attention on e-commerce product is captured by eye tracker connected with consumer computer. One of eye tracking data collected by eye tracker is fixation duration (FD). To discover that the fixation is on a product, the AOI must be identified by using a square that covers the product. Consumer attention in e-commerce product can be measured by total FD of consumer on a product. This process needs product information and consumer profile. After consumer attention is defined by total FD, the next process is calculating the prediction of purchase (C) of that product using Chandon model [10], [22]. The result 


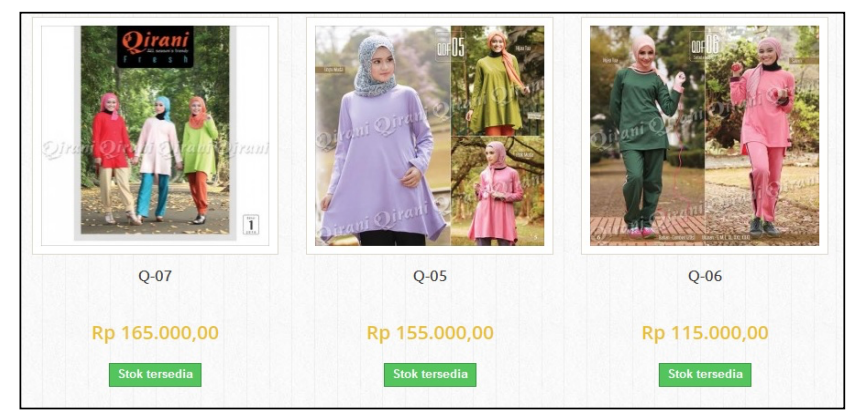

Fig. 4 Catalog1.

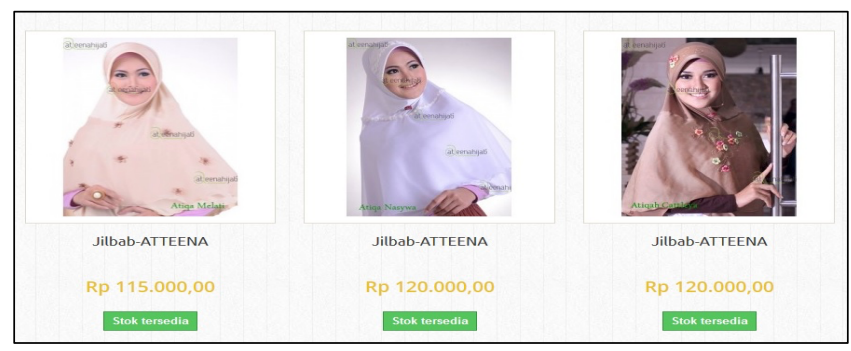

Fig. 5 Catalog2.

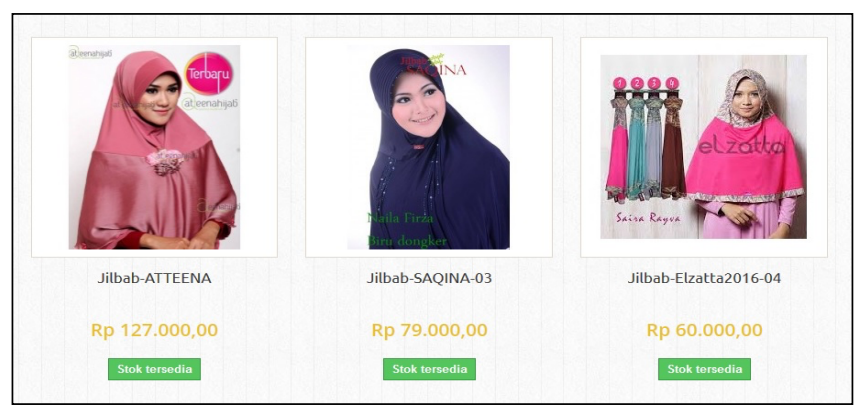

Fig. 6 Catalog3.

of prediction of purchase can be used as transaction data, while FD can be used as consumer interest data. Both data are used in product recommendation by using item-to-item collaborative filtering method. The advantage of both data is that consumers' interest of the product can be recognized and the opportunity whether they purchase that product or not can be predicted. Product recommendations from both data will help other consumers to choose the product as they wish.

Fixation duration and prediction of purchase data are changed in level forms to make the product recommendations by utilizing the following rules.

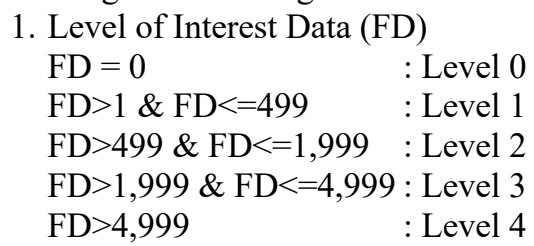

2. Level of Prediction of Purchase Data (C)
$\mathrm{C}<0.001$
: Level 0
$\mathrm{C}>=0.001 \& \mathrm{C}<0.002$
: Level 1
$\mathrm{C}>=0.002 \& \mathrm{C}<0.003 \quad$ : Level 2
$\mathrm{C}>=0.003 \& \mathrm{C}<0.004 \quad$ : Level 3
$\mathrm{C}>=0.004 \quad:$ Level 4

When $\mathrm{C}$ data of the product has level 4 , it is assumed that the product is purchased by consumer. The FD level was used when calculating the similarity of the product.

The product recommendations method that is used in this research is the item-to-item collaborative filtering with the following algorithm: scanning on consumer $\mathrm{C} 1$ who purchased the first product, then scanning the second product purchased by consumer $\mathrm{C} 1$. This is done until the last consumer. The next step is to look for similarity of products purchased by consumers $\mathrm{C} 1$ and other consumers using the Pearson coefficient formula. Fig. 3 describes the flowchart of item-toitem collaborative filtering.

\section{EXPERIMENT}

This experiment was conducted to implement the model of product recommendation based on eye tracking data. The followings are the preparation of experiment.

\section{A. Apparatus}

Experiment of product recommendation based on eye tracking data used eye tracker sensor called Eye Tribe eye tracker to capture consumer interest. The specifications were table sampling rate of $30 \mathrm{~Hz}$ and $60 \mathrm{~Hz}$ mode, accuracy of 0.5 '1 , operating range of $45 \mathrm{~cm}-75 \mathrm{~cm}$. The computer for running e-commerce was utilizing these specifications: Intel core i3, 2 GB DDR 3, 1 TB HDD, monitor 14", resolution of $1366 \times 768$. Software that was used to get eye tracking data, which was fixation duration, was Eyeproof while software for processing data eye tracking was Microsoft Excel.

\section{B. Stimulus}

The experiments were conducted using the e-commerce site of selvahouse.com which sells hijab and women's modest wear. The e-commerce catalogues shown to the consumers were three slides catalog hijab image, namely catalog1, catalog2, and catalog3. The catalogues can be seen in Fig. 4, Fig. 5 and Fig. 6.

\section{Experimental Design}

The experiment's design was within subject since there was only one group and one test condition. The test was conducted by asking each participant to see the slide of the catalog in selvahouse.com. In each slide contained three images.

\section{Participant}

The participants in this experiment were 14 female students of Polytechnic ABC in Pekanbaru, Riau, Indonesia aged 17-21 years old. The recruiting of participants through word of mouth.

\section{E. Procedure}

Before the experiment began, the participants were given insight about the experiment's objective and the scenario. The objective of experiment was to know the consumer interest to product. The data would be used to find prediction of purchase data, then the product recommendation could be made by calculating both data. The followings are scenarios used in this experiment. 
TABLE I

DATA OF CONSUMER INTEREST ON THE PRODUCT AND INTEREST LEVEL OF CATALOG1

\begin{tabular}{|c|c|c|c|c|c|c|}
\hline \multirow{2}{*}{ Consumer } & \multicolumn{3}{|c|}{ Fixation Duration } & \multicolumn{3}{c|}{ Interest Level } \\
\cline { 2 - 7 } & $\boldsymbol{F D 1}$ & $\boldsymbol{F D 2}$ & $\boldsymbol{F D 3}$ & $\boldsymbol{F D 1}$ & $\boldsymbol{F D 2}$ & $\boldsymbol{F D 3}$ \\
\hline 1 & 2,099 & 1,962 & 1,844 & 3 & 2 & 2 \\
\hline 2 & 294 & 6,325 & 691 & 1 & 4 & 2 \\
\hline 3 & 2,204 & 3,403 & 1,237 & 3 & 3 & 2 \\
\hline 4 & 1,749 & 4,124 & 1,612 & 2 & 3 & 2 \\
\hline 5 & 1,386 & 4,686 & 2,354 & 2 & 3 & 3 \\
\hline 6 & 1,250 & 4,759 & 1,286 & 2 & 3 & 2 \\
\hline 7 & 1,319 & 5,309 & 533 & 2 & 4 & 2 \\
\hline 8 & 1,467 & 3,984 & 2,597 & 2 & 3 & 3 \\
\hline 9 & 2,376 & 1,561 & 518 & 3 & 2 & 2 \\
\hline 10 & 2,101 & 4,008 & 668 & 3 & 3 & 2 \\
\hline 11 & 1,328 & 2,870 & 1,950 & 2 & 3 & 2 \\
\hline 12 & 3,441 & 1,877 & 459 & 3 & 2 & 1 \\
\hline 13 & 985 & 5,548 & 1,546 & 2 & 4 & 2 \\
\hline 14 & 0 & 1,549 & 1,952 & 0 & 2 & 2 \\
\hline
\end{tabular}

TABLE II

Product Purchase Prediction Data And Purchase Prediction LeVEL OF CATALOG1

\begin{tabular}{|c|c|c|c|c|c|c|}
\hline \multirow{2}{*}{ Consumers } & \multicolumn{3}{|c|}{$\begin{array}{c}\text { Product Purchase } \\
\text { Prediction }\end{array}$} & \multicolumn{3}{c|}{$\begin{array}{c}\text { Purchase } \\
\text { Prediction } \\
\text { Level }\end{array}$} \\
\cline { 2 - 7 } & $\boldsymbol{C 1}$ & $\boldsymbol{C 2}$ & $\boldsymbol{C 3}$ & $\boldsymbol{C 1}$ & $\boldsymbol{C 2}$ & $\boldsymbol{C 3}$ \\
\hline 1 & 0.0033 & 0.0026 & 0.0031 & 3 & 2 & 3 \\
\hline 2 & 0.0009 & 0.0063 & 0.0019 & 0 & 4 & 1 \\
\hline 3 & 0.0035 & 0.0041 & 0.0022 & 3 & 3 & 2 \\
\hline 4 & 0.0022 & 0.0051 & 0.0022 & 2 & 4 & 2 \\
\hline 5 & 0.0011 & 0.0064 & 0.0029 & 1 & 4 & 2 \\
\hline 6 & 0.0013 & 0.0060 & 0.0022 & 1 & 4 & 2 \\
\hline 7 & 0.001 & 0.0081 & 0.0005 & 1 & 4 & 0 \\
\hline 8 & 0.0016 & 0.0038 & 0.0047 & 1 & 3 & 3 \\
\hline 9 & 0.0041 & 0.0025 & 0.0004 & 3 & 2 & 0 \\
\hline 10 & 0.0031 & 0.0053 & 0.0014 & 3 & 4 & 1 \\
\hline 11 & 0.0015 & 0.004 & 0.0042 & 1 & 3 & 3 \\
\hline 12 & 0.0046 & 0.0033 & 0.0007 & 3 & 3 & 0 \\
\hline 13 & 0.0017 & 0.0061 & 0.0022 & 1 & 4 & 2 \\
\hline 14 & 0 & 0.0039 & 0.0048 & 0 & 3 & 3 \\
\hline
\end{tabular}

1. Participants did the calibration process while using eye tracker.

2. Participants did an eye tracking study on images in catalog1, catalog2 and catalog3. The views of respondents were captured by the Eye Tribe and would be analyzed using the Eyeproof software analysis. The data was the FD showing information of how long consumers paid attention to the product's area.

3. FD data were calculated to produce C. Both data were converted to FD and level to C.

4. Product recommendations were made by finding the similarity of the level 4 of prediction data in every product that consumer is interested in. The level 4 of prediction data represented the purchased products.
TABLE III

Prediction LeVEls of All Products

\begin{tabular}{|c|c|c|c|c|c|c|c|c|c|}
\hline \multirow{2}{*}{ Consumer } & \multicolumn{7}{|c|}{ Purchase prediction } \\
\cline { 2 - 11 } & $\mathbf{3 1}$ & $\mathbf{3 2}$ & $\mathbf{3 3}$ & $\mathbf{5 1}$ & $\mathbf{5 2}$ & $\mathbf{5 3}$ & $\mathbf{6 1}$ & $\mathbf{6 2}$ & $\mathbf{6 3}$ \\
\hline 1 & 3 & 2 & 3 & 3 & 2 & 3 & 0 & 3 & 3 \\
\hline 2 & 0 & 4 & 1 & 1 & 4 & 1 & 0 & 4 & 0 \\
\hline 3 & 3 & 3 & 2 & 4 & 2 & 0 & 1 & 4 & 0 \\
\hline 4 & 2 & 4 & 2 & 2 & 4 & 1 & 0 & 3 & 4 \\
\hline 5 & 1 & 4 & 2 & 1 & 1 & 4 & 2 & 2 & 3 \\
\hline 6 & 1 & 4 & 2 & 3 & 0 & 3 & 0 & 1 & 4 \\
\hline 7 & 1 & 4 & 0 & 2 & 4 & 0 & 0 & 4 & 3 \\
\hline 8 & 1 & 3 & 3 & 3 & 3 & 2 & 1 & 1 & 4 \\
\hline 9 & 3 & 2 & 0 & 2 & 3 & 3 & 0 & 3 & 3 \\
\hline 10 & 3 & 4 & 1 & 2 & 0 & 4 & 2 & 2 & 3 \\
\hline 11 & 1 & 3 & 3 & 0 & 4 & 3 & 4 & 2 & 1 \\
\hline 12 & 3 & 3 & 0 & 1 & 2 & 3 & 3 & 2 & 2 \\
\hline 13 & 1 & 4 & 2 & 1 & 4 & 1 & 4 & 1 & 0 \\
\hline 14 & 0 & 3 & 3 & 0 & 0 & 4 & 3 & 1 & 1 \\
\hline
\end{tabular}

TABLE IV

LEVEL OF INTEREST

\begin{tabular}{|c|c|c|c|c|c|c|c|c|c|}
\hline \multirow{2}{*}{ Cons. } & \multicolumn{10}{|c|}{ Level of Interest } \\
\cline { 2 - 11 } & $\mathbf{3 1}$ & $\mathbf{3 2}$ & $\mathbf{3 3}$ & $\mathbf{5 1}$ & $\mathbf{5 2}$ & $\mathbf{5 3}$ & $\mathbf{6 1}$ & $\mathbf{6 2}$ & $\mathbf{6 3}$ \\
\hline 1 & 3 & 2 & 2 & 2 & 2 & 3 & 2 & 3 & 3 \\
\hline 2 & 1 & 4 & 2 & 2 & 3 & 2 & 1 & 4 & 1 \\
\hline 3 & 3 & 3 & 2 & 3 & 2 & 1 & 2 & 3 & 1 \\
\hline 4 & 2 & 3 & 2 & 2 & 3 & 2 & 1 & 3 & 4 \\
\hline 5 & 2 & 3 & 3 & 2 & 2 & 3 & 2 & 2 & 3 \\
\hline 6 & 2 & 3 & 2 & 3 & 1 & 3 & 1 & 2 & 4 \\
\hline 7 & 2 & 4 & 2 & 2 & 3 & 2 & 2 & 3 & 2 \\
\hline 8 & 2 & 3 & 3 & 2 & 3 & 2 & 1 & 2 & 4 \\
\hline 9 & 3 & 2 & 2 & 2 & 3 & 3 & 1 & 3 & 2 \\
\hline 10 & 3 & 3 & 2 & 2 & 2 & 3 & 2 & 3 & 2 \\
\hline 11 & 2 & 3 & 2 & 1 & 3 & 3 & 3 & 2 & 2 \\
\hline 12 & 3 & 2 & 1 & 2 & 3 & 3 & 3 & 2 & 3 \\
\hline 13 & 2 & 4 & 2 & 2 & 3 & 2 & 4 & 2 & 1 \\
\hline 14 & 0 & 2 & 2 & 0 & 0 & 4 & 3 & 2 & 1 \\
\hline Avr. & 2.14 & 2.93 & 2.07 & 1.93 & 2.36 & 2.57 & 2.00 & 2.57 & 2.36 \\
\hline
\end{tabular}

\section{F. Experiment Result}

From the result, there were FD data of consumer to products on three catalogs. The FD data were calculated to get C. After that, FD and $\mathrm{C}$ were converted to level FD and level C. Table I shows the FD data and level of FD of participants on catalog1, while Table II shows the $\mathrm{C}$ data and level of $\mathrm{C}$ of participants on catalog1. The fixation duration and prediction data of calat $\log 2$ and catalog3 were also converted in levels. After that, the three data were combined and shown in Table III and Table IV. The product recommendations were made by finding prediction data of level 4 which was representing the purchased products. Then, all purchased products were calculated to find similar products. The calculation results are shown in Table V. From Table V, the results obtained show several values: 1 is the similarity of the product. There are also a number smaller than 1. According to the reference, if the value of similarity is -1 , then the product is not similar. If the value of similarity is $0<\operatorname{sim}<1$, the product is similar but not quite the same. If the 
TABLE V

PRODUCT SIMILARITY

\begin{tabular}{|l|r|}
\hline Product32 & Similarity \\
\hline Calculation of product similarity 32 to 52 & 0.884615 \\
\hline Calculation of product similarity 32 to 62 & 0.880471 \\
\hline Calculation of product similarity 32 to 63 & 0.863479 \\
\hline Calculation of product similarity 32 to 53 & 1 \\
\hline & Similarity \\
\hline Product52 & 0.884615 \\
\hline Calculation of product similarity 52 to 32 & 0.880471 \\
\hline Calculation of product similarity 52 to 62 & 1 \\
\hline Calculation of product similarity 52 to 63 & 0.948683 \\
\hline Calculation of product similarity 52 to 61 & \\
\hline & Similarity \\
\hline Product51 & 1 \\
\hline Calculation of product similarity 51 to 62 & Similarity \\
\hline & 1 \\
\hline Product53 & Similarity \\
\hline Calculation of product similarity 53 to 32 & 0.948683 \\
\hline & 0.880471 \\
\hline Product62 & 0.880471 \\
\hline Calculation of product similarity 62 to 32 & 1 \\
\hline Calculation of product similarity 62 to 52 & 0.863479 \\
\hline Calculation of product similarity 62 to 51 & 1 \\
\hline & \\
\hline Product63 & \\
\hline Calculation of product similarity 63 to 32 & \\
\hline Calculation of product similarity 63 to 52 & \\
\hline & \\
\hline Product61 & \\
\hline Calculation of product similarity 61 to 52 & \\
\hline
\end{tabular}

TABLE VI

LIST OF PRODUCT RECOMMENDATION

\begin{tabular}{|c|l|}
\hline Product & \multicolumn{1}{|c|}{ Similar Product } \\
\hline 32 & $53,63,52,62$ \\
\hline 52 & $63,61,32,62$ \\
\hline 51 & 62 \\
\hline 53 & 32 \\
\hline 62 & $51,52,32$ \\
\hline 63 & 52,32 \\
\hline 61 & 52 \\
\hline
\end{tabular}

value of similarity is $=1$, the product is similar. In this experiment, it was determined that the value of the similarity of $0.5<\operatorname{sim}<1$ was included in the list of product recommendations.

In Table $\mathrm{V}$, the products included in the recommendation list are product 32 that was similar to product 53 , product 63 , product 52 and product 62 ; product 52 that was similar to product 63 , product 61 , product 32 and product 62 ; and product 51 that was similar to product 62 . Therefore, the consumers who are interested in product 32 will be recommended to see product 53 , product 52 , product 62 and product 63 . Consumers who are interested in product 52 will be recommended to see product 63 , product 61 , product 32 and product 62 . Consumers who are interested in product 51 will be recommended to see product 62. The list of product recommendation is described in Table VI.

\section{G. Discussion}

Shopping using e-commerce has more advantages as consumers can shop more efficiently. However, since there are many products offered, consumers might get a lot of information so that online shopping becomes inefficient. One solution to overcome overloaded information is by providing product recommendations. The benefit of the product recommendations is that consumers do not need much time to choose a product because the list of highly purchased products, products that match consumer preferences, and products similar to those purchased by other consumers are all already available.

The product recommendations require the transaction data and product rating data from consumers. Therefore, the recommendations of the product will be given when the consumers have made transactions. Innovation in this research is that the product recommendations can be given when the consumers do the shopping activities because the product recommendations are made based on the data of the consumer interest. Then, the data of the consumer interest is processed into predicted data of the product purchase. From these two data, product recommendations using the interest data representing product rating data and predictive purchase data representing transaction data were made.

An experiment has been done by using selvahouse.com site resulting some products which have similarities to other products. It can be seen in Table $\mathrm{V}$ and Table IV. When compared to Table I and Table II of the catalog1, the consumers who are willing to buy product 32 (catalog1 product2) are also eager to buy product 52 (catalog2 product2). It also occurs on catalog2 and catalog3. Therefore, by using the item-to-item collaborative filtering method and eye tracking data, the product recommendations can be built.

\section{CONCLUSION}

The internet development and sensor technology enable the integration of technology in innovation, such as shopping with e-commerce using internet technology. In shopping, there are several consumer behaviors that can be observed, including consumer interest in a product. As the development of the sensor technology, the consumer interest in the object, in this case, is in e-commerce products, can be caught by using the eye tracker tool that detects eye movements using infrared.

The detection of the consumer interest in the earlier ecommerce products will provide benefits to consumers and sellers. The existence of the consumer interest data can be used to generate the prediction data of the product purchase. From these two data, product recommendations can be built where previous product recommendations require the transaction data and product rating data. The product recommendation will provide a list of products that are following the interest of the consumers because it is built based on the evaluation of products by consumers and consumers' desire. The product purchase prediction data are assumed as the transaction data; meanwhile, the interest data are assumed as consumer rating to 
product called product rating data. The product recommendation based on the eye tracking data using item-toitem collaborative filtering method can provide a recommendation list according to data analysis on the prediction data and interest data.

Based on the result of the experiment, list of product recommendation on Table IV shows that products 32, 52, and 62 are favorite items since they have similarity with other product more than one. It means that products 32,52 , and 62 are often bought along with other product. Therefore, the consumer that buy product 32 will be recommended to buy four products that are similar with product 32 .

The development of the product recommendations based on the eye tracking data is adjusted with catalogs in e-commerce which consist of the model, brand, and price. The consumer interest in the product can be seen from the model, brand, or price. Further research will examine those items since knowing the focus of the consumer interest will provide information for marketing to increase sales.

\section{ACKNOWLEDGEMENT}

Thank you to Mrs. Elva Susianti as the owner of selvahouse.com for allowing the author to use Selvahouse's products for the experiment.

\section{REFERENCES}

[1] M.R. Siddiquee, N. Haider, and R.M. Rahman, "A Fuzzy Based Recommendation System with Collaborative Filtering," The 8th International Conference on Software, Knowledge, Information Management and Applications (SKIMA 2014), 2014, pp. 1-8.

[2] G. Linden, B. Smith, and J. York, "Amazon.com Recommendation: Item to Item Collaborative Filtering," IEEE Internet Computing, Vol. 7, No. 1, pp. 76-80, Jan.-Feb. 2003.

[3] X. Zhao, Z. Niu, and W. Chen, "Interest before Liking: Two-Step Recommendation Approaches," Knowledge-Based System, Vol. 48, No. 1, pp. 46-56, Aug. 2013.

[4] Q. Su and L. Chen, "A Method for Discovering Clusters of E-Commerce Interest Patterns Using Click-Stream Data," Electronic Commerce Research and Applications, Vol. 14, No. 1, pp. 1-13, Jan. 2015.

[5] D.S. Sisodia, "Augmented Session Similarity Based Framework for Measuring Web User Concern from Web Server Logs," International Journal on Advanced Science, Engineering and Information Technology, Vol. 7, No. 3, pp. 1007-1013, Jun. 2017.

[6] F. Hafizhelmi, K. Zaman, H. Ali, A.A. Shafie, and Z.I. Rizman, "Efficient Human Motion Detection with Adaptive Background for Vision-Based Security System," International Journal on Advanced Science, Engineering and Information Technology, Vol. 7, No. 3, pp. 1026-1031, Jun. 2017.
[7] A. Poole and L.J. Ball, "Eye Tracking in Human-Computer Interaction and Usability Research: Current Status and Future Prospects," in Encyclopedia of Human Computer Interaction, C. Ghaoui, Ed., Pennsylvania, USA: Idea Group Reference, 2006, pp. 211-219.

[8] S. Djamasbi, A. Hall-Phillips, and R.R. Yang, "Search Results Pages and Competition for Attention Theory: An Exploratory Eye-Tracking Study," in Human Interface and the Management of Information. Information and Interaction Design, S. Yamamoto, Ed., Heidelberg, Germany: Springer, 2013, pp. 576-583.

[9] J. Wehrmeyer, "Eye-Tracking Deaf and Hearing Viewing of Sign Language Interpreted News Broadcasts," Journal of Eye Movement Research, Vol. 7, No. 1, pp. 1-16, Mar. 2014.

[10] P. Chandon, J.W. Hutchinson, E.T. Bradlow, and S.H. Young, "Measuring the Value of Point-of-Purchase Marketing with Commercial Eye-Tracking Data," in Visual Marketing: From Attention to Action, M. Wedel and R. Pieters, Eds., Mahwah, New Jersey: Lawrence Erlbaum Associates, 2007, pp. 225-258.

[11] S. Wilson and I. Abel, "So You Want to Get Involved in E-Commerce," Industrial Marketing Management, Vol. 31, Vol. 2, pp. 85-94, Feb. 2002.

[12] G. Schneider, Electronic Commerce, 9th ed. Boston, USA: Cengage Learning, 2013.

[13] F. Al-Qaed and A. Sutcliffe, "Adaptive Decision Support System (ADSS) for B2C E-Commerce," Proceedings of the 8th International Conference on Electronic Commerce: The New E-Commerce: Innovations for Conquering Current Barriers, Obstacles and Limitations to Conducting Successful Business on the Internet, 2006, pp. 492-503.

[14] P. Xia, J. Xiao, and S. Chen, "An Application of Recommender System with Mingle-TopN Algorithm on B2B Platform," 2013 International Conference on Advanced Cloud and Big Data, 2013, pp. 170-176.

[15] P. Liu and L. Hai, "Application of Sequence Alignment Technique to Collaborative Recommendations in E-Commerce," 2010 International Conference on E-Product E-Service and E-Entertainment, 2010, pp. 1-3.

[16] M.M. Rahman, "Contextual Recommendation System," Proceeding of the 2013 International Conference on Informatics, Electronics and Vision (ICIEV), 2013, pp. 1-6.

[17] B. Sarwar, G. Karypis, J. Konstan, J. Riedl, "Item-Based Collaborative Filtering Recommendation Algorithms," Proceedings of the 10th International Conference on World Wide Web, 2001, pp. 285-295.

[18] A. Bojko, Eye Tracking the User Experience: A Practical Guide to Research. New York, USA: Rosefeld Media, 2013.

[19] J.N. Sari, L.E. Nugroho, P.I. Santosa, and R. Ferdiana, "Evaluation of Fixation Duration Accuracy in Determining Selected Product on ECommerce," 2018 10th International Conference on Information Technology and Electrical Engineering (ICITEE), 2018, pp. 146-151.

[20] I. Krajbich, D. Lu, C. Camerer, and A. Rangel, "The Attentional DriftDiffusion Model Extends to Simple Purchasing Decisions," Frontiers in Psychology, Vol. 3, Jun. 2012.

[21] M. von Boguslawski and P. Mildén, "The Attentional Drift-Diffusion Model for Simple Choice in the Quaternary Case, Measuring the Effect of Permutation of Item Location on Choice Behaviour," Nov. 14.

[22] J.N. Sari, L.E. Nugroho, P.I. Santosa, and R. Ferdiana, "The Measurement of Consumer Interest and Prediction of Product Selection in E-Commerce Using Eye Tracking Method," International Journal of Intelligent Engineering and Systems, Vol. 11, No. 1, pp. 30-40, Feb. 2018. 